\title{
LA EVOLUCIÓN HACIA MODELOS HETEROGÉNEOS EN EL MONTE VECINAL ATLÁNTICO
}

\section{Ricardo Suárez García}

Institución: Universidad Pablo de Olavide. Sevilla.Email: ricardosrga@gmail.com

Palabras clave: Metabolismo agrario. Despoblación. Comunales. Identidad. Rural.

\section{Introducción, justificación, metodología y marco teórico}

Este trabajo pretende estudiar la capacidad de adaptación de las comunidades de Montes Veciñais en Man Común de Galicia entre la década de los sesenta y la actualidad. Nos interesa especialmente analizar el proceso de reinvención que algunas de estas comunidades realizaron tras la recuperación de la propiedad entre las décadas de los setenta y ochenta del siglo XX.

Esta recuperación sucedió tras tres décadas de desposesión y de forestación forzosa que alteraron sustancialmente la relación de los vecinos con los espacios comunales. En segundo lugar, la devolución se produjo en un momento en el que la agricultura gallega estaba sufriendo un proceso de industrialización rápido en el que los espacios no cultivados se orientaron hacia una especialización forestal completamente desvinculados de la principal línea de especialización de la agricultura gallega, la ganadera láctea (Soto, 2015). Todos estos procesos combinados produjeron una triple ruptura en los montes vecinales gallegos: una ruptura económica y biofísica en la funcionalidad de los comunales en los agroecosistemas gallegos, una ruptura institucional con la adopción de un modelo organizativo nuevo creado por las leyes y una ruptura identitaria, en el significado que los espacios comunales tenían para las comunidades.

A través de 5 casos de estudio de comunidades de MVMC de la zona atlántica gallega trataremos de ejemplificar ciertos aspectos sobre como esta triple ruptura ha obligado a estas comunidades a adoptar nuevos enfoques dinámicos de explotación del monte para adaptarse a un nuevo tiempo que han resultado en la aparición de tipologías diversas de las mismas.

Mapa 1: Localización de los casos de estudio

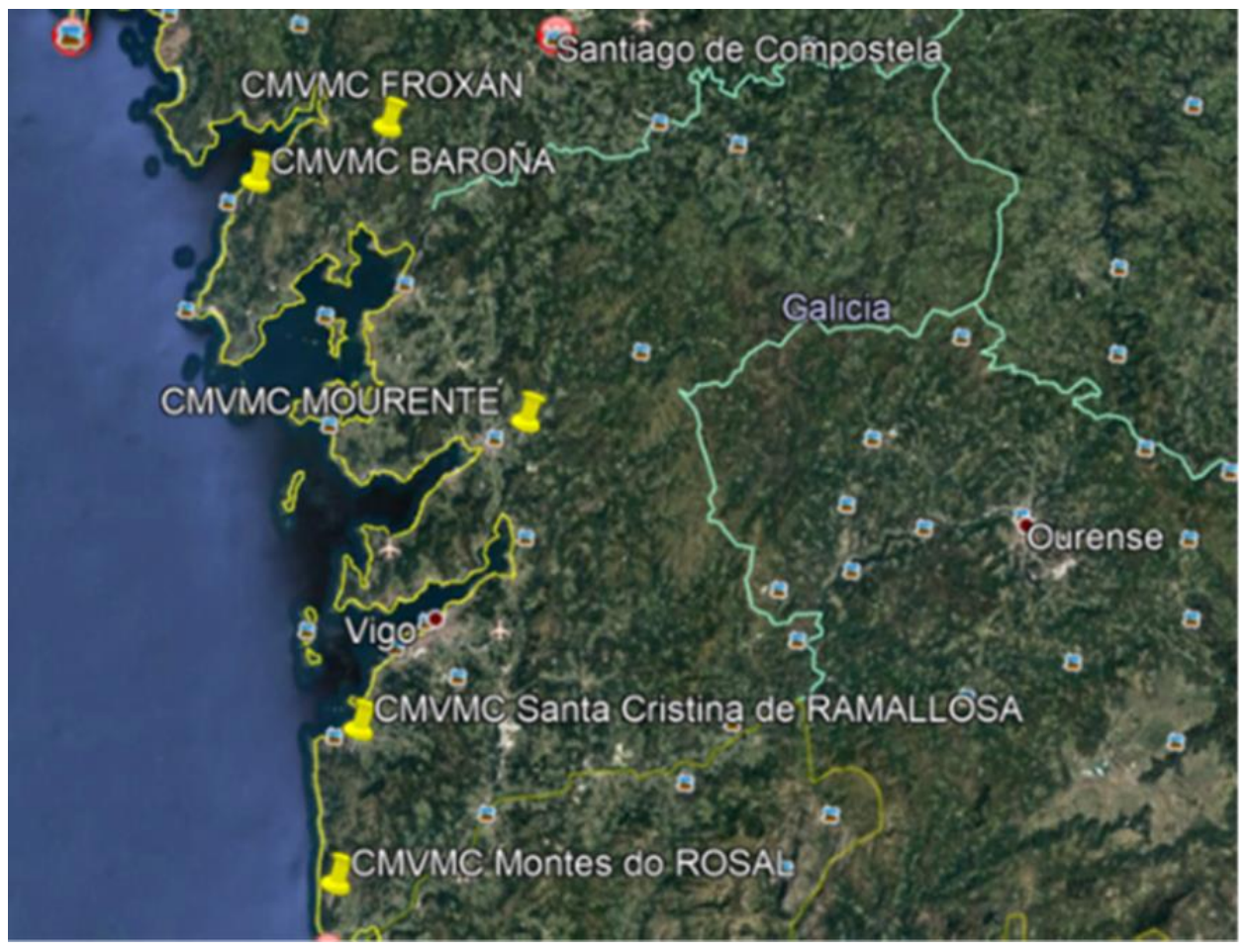

Fuente: Elaboración propia con google maps 


\section{La creación de nuevos significados sobre el comunal}

Los procesos de repoblación forzosa del franquismo están ligados a una expropiación efectiva de la propiedad atribuida a los municipios y a un paréntesis largo en la gestión vecinal que supuso una ruptura en la historia institucional de los montes vecinales gallegos. Este proceso, coincidente cronológicamente con la transformación productiva anteriormente descrita, obtuvo una contestación que peligró el proceso repoblador y obligó a la dictadura a buscar fórmulas de apaciguamiento. En este contexto aparece la Ley de Montes Vecinales en Mano Común, de 1968, que abre la puerta a la recuperación de la propiedad por las comunidades, en un proceso de reclamaciones vecinales que se extiende a lo largo de la década de los setenta y primeros ochenta, y que, aunque de manera mucho más limitada, continúa hasta hoy. Lo más relevante desde el punto de vista institucional es que ni esta norma ni las siguientes suponen una recuperación de la comunidad tradicional, mayoritariamente consuetudinaria, sino una reinvención que tendrá consecuencias en las formas que las comunidades se organizaran a lo largo del periodo democrático.

Tres características básicas definen a la comunidad campesina: el aprovechamiento doméstico de recursos colectivos; un aprovechamiento que no era ni se entendía como igualitario, ya que aunque la titularidad es indiferenciada y el disfrute jurídicamente igualitario el aprovechamiento es mayor en aquellas casas con más tierras, ganado y fuerza de trabajo; y, en tercer lugar, que aunque la gestión era colectiva, tampoco era igualitaria, sino que la desigualdad social afectaba en la toma de decisiones.

Sin embargo, la ley de 1968 y especialmente las siguientes parten de una concepción claramente igualitaria en el acceso y en los aprovechamientos, así como en una gestión colectiva (y posteriormente democrática) de los mismos. En este sentido y aunque el comunal es y se percibe como privado, su gestión se asemeja más a un bien público que a un recurso de uso individual, hecho comprensible si entendemos que se estaba intentando privilegiar el aprovechamiento forestal con el proceso de devolución. Espacios poseídos colectivamente, pero gestionados por las unidades domésticas, pasan a ser poseídos y gestionados colectivamente, ya que, aunque las leyes permiten el reparto de beneficios, privilegian claramente su reinversión o uso comunitario (Balboa et al., 2006).

Cambios que tendrán consecuencias directas en la organización, el funcionamiento y la toma de decisiones de las comunidades. Desde el punto de vista institucional la vieja y la nueva comunidad son radicalmente distintas. Desde una concepción identitaria, también se produce una fractura en torno a la década de los setenta, pasando de comunidades concebidas mayoritariamente como parte de los agroecosistemas locales a comunidades percibidas como proveedoras de servicios materiales e inmateriales.

Durante el proceso de reclamación y posteriormente ambas visiones convivirán mientras pervive en mayor o menor medida la memoria de la vieja comunidad. Argumento este último que concuerda con el choque de visiones al que hacía referencia el presidente de la comunidad de MVMC de Santa Cristina de Ramallosa en la que señalaba tener constancia de la existencia de dos visiones enfrentadas entre aquellas de las generaciones que habían vivido el aprovechamiento tradicional de las tierras y aquellas generaciones ya desvinculadas del mismo. Mientras los primeros se mostraban desfavorables a la pérdida de la relación entre la producción agrícola y los montes vecinales y todavía hoy siguen argumentando desde la resignación y quizás con cierta nostalgia que la pérdida del antiguo modelo y la adopción de una estrategia productivista forestal conllevaría y conlleva consecuencias negativas para las comunidades, los más jóvenes observaban con buenos ojos la apuesta por la producción forestal en la que veían una oportunidad para modernizar el aprovechamiento de los montes y desarrollar la comunidad. Esta afirmación también se ve corroborada, en un momento tan tardío como el año 2000, en una encuesta realizada a comuneros de varias comunidades en la que aún persistía este choque de visiones (Balboa et al., 2006).

Dentro de esta amalgama de diferentes usos y formas de entender el monte cabe destacar el avance de la multifuncionalidad de muchos de ellos. La nueva ola de comunidades actuales no ha producido solo la heterogeneidad de modelos de gestión diferenciada entre unas y otras, sino que también ha supuesto la heterogeneidad de aprovechamientos en el interior de estas. Esta heterogeneidad se puede discernir tanto de forma material a través de las formas de aprovechamiento como de forma inmaterial a través de las significaciones que la pertenencia a la comunidad tiene para la población local.

A través de los ejemplos explorados, pertenecientes todas ellas a la franja atlántica, constatamos, tanto desde el punto de vista de la construcción de una nueva institucionalidad, como desde el punto de vista de 
la reinvención del comunal en términos identitarios, que entre las nuevas tipologías de comunidades de monte vecinal que está surgiendo una gran heterogeneidad y adaptación al contexto del espacio donde se encuentra cada una de ellas. Sin embargo, todas estas experiencias comparten el hecho de haber superado la rotura del equilibrio agro-silvo-pastoril a través de esta adaptación y la construcción de una nueva identidad y conexión entre la población y el monte.

Cuadro 1. Características de los casos de estudio

\begin{tabular}{|l|l|l|l|l|}
\hline CMVMC & Hectáreas & Comuneras & $\begin{array}{l}\text { Generación de } \\
\text { empleo }\end{array}$ & $\begin{array}{l}\text { Modelo } \\
\text { predominante }\end{array}$ \\
\hline O Rosal & 1500. & 325. & Si. 10/18. & $\begin{array}{l}\text { Forestal } \\
\text { productivista. }\end{array}$ \\
\hline Baroña & 846. & 186. & Si. 13. & $\begin{array}{l}\text { Forestal } \\
\text { multifuncional. }\end{array}$ \\
\hline Mourente & 44. & 170. & No. & $\begin{array}{l}\text { Conservacionismo } \\
\text { paisajístico. }\end{array}$ \\
\hline Froxán & 100. & 4. & No. & $\begin{array}{l}\text { Conservacionismo } \\
\text { militante. }\end{array}$ \\
\hline Ramallosa & 107. & 140. & Si. 4. & $\begin{array}{l}\text { Forestal } \\
\text { conservacionista. }\end{array}$ \\
\hline
\end{tabular}

Fuente: Elaboración propia

La clasificación del cuadro 1, que surge de la investigación de cada uno de los casos, reafirma la idea de que la reinvención en términos materiales, identitarios y de gestión genera modelos heterogéneos de comunidad. La caracterización de la CMVMC de O Rosal como forestal productivista responde al hecho de que, a pesar de realizar acciones de conservación y prevención ecológica, su modelo de explotación gira alrededor de la generación de rentas de la madera para su reinversión en la comunidad. Una caracterización que se puede contraponer con el modelo de gestión de Ramallosa, que, a pesar de girar también alrededor de la explotación forestal, en este caso es en gran medida para reinvertir las rentas en la conservación del espacio. Otro tipo de caracterización es la de las comunidades en las que la explotación de la madera ya no juega un papel central apostando directamente por la conservación del entorno, dentro de estas diferenciamos entre el conservacionismo militante de Froxán donde existe un componente ideológico muy fuerte con el conservacionismo paisajístico de Mourente donde prevalece la intención de tener un espacio verde para el esparcimiento de la población urbana y periurbana. Un último modelo es el de Baroña, al que hemos llamado forestal multifuncional, ya que a pesar de que el aprovechamiento forestal sigue teniendo gran importancia se compagina con una gran multitud de aprovechamientos de diversos tipos.

\section{Conclusiones}

A partir de los años 90 se puede hablar de un nuevo impulso en el monte vecinal gallego que lleva a una nueva heterogeneidad de comunidades. Es a partir de este momento cuando se empieza a percibir claramente un proceso de reinvención del comunal más allá del modelo productivista forestal, aunque en ningún caso se produzca una vuelta al modelo de gestión comunal de la comunidad campesina orgánica.

En este contexto aparece una gran diversidad de maneras de entender el aprovechamiento del monte adaptadas a las necesidades y cosmovisiones de cada comunidad. Y es precisamente esta capacidad de resiliencia ante las nuevas condiciones socioeconómicas, la adaptación de los modelos a las oportunidades que ofrece cada MVMC y su contexto y la aparición de otros modelos de gestión ejemplificadores lo que provoca que muchos de los MVMC en situación de abandono o infrautilización estén reflotando en el presente.

Los ejemplos recogidos en este trabajo no son extrapolables al conjunto de las comunidades de montes de Galicia, muchas de las cuales se encuentran en estado de abandono, pero representan ejemplos de buenas 
prácticas que podrían ser aprovechadas en otros casos. Para un número importante de comunidades de MVMC en la zona de la franja atlántica se observa una nueva reconceptualización del aprovechamiento del monte que está permitiendo la pervivencia de este tipo de instituciones bajo unos nuevos parámetros.

\section{Bibliografía}

\section{Artículos:}

Balboa, X.; Besteiro, B.; Fernández, X.; Fernández, X.; Jordán, M.; López, E.; Soto, D.; Viso, P. (2004). "La devolución de la propiedad vecinal en Galicia (1960-1985). Modos de uso y conflicto de propiedad", Historia Agraria, 33, pp. 105-130.

Gallego, D. (2013). Las distintas caras de la economía institucional. XIII Congreso de la SEHA.

Soto, D.; Herrera, A.; González de Molina, M. y Ortega, A. (2007). "La protesta campesina como protesta ambiental, siglos XVIII-XX", Historia Agraria, 42, pp. 277-301.

Soto, D. (2015). Del manejo multifuncional del territorio a la desarticulación productiva: cambios en los flujos de biomasa durante el proceso de industrialización de la agricultura gallega (1960-2012). Documentos de Trabajo SEHA, DT-SEHA 1505.

Soto, D., Infante-Amate, J., Guzmán, G.I., Cid, A., Aguilera, E., García, R., González de Molina, M. (2016). "The Social Metabolism of Biomass in Spain, 1900-2008: from food to feed-oriented changes in the Agroecosystems", Ecological Economics, 128, pp. 130-138. DOI 10.1016/j.ecolecon.2016.04.017

\section{Libros:}

Balboa, X. (1990). O Monte en Galicia. Xerais.

Balboa, X.; Besteiro, B.; Fernández, X.; Fernández, L.; Jordán, M.; López, E.; Soto, D.; Viso, P. (2006). Os montes veciñais en man común: o patrimonio silente. Naturaleza, economía, identidade e democracia na Galicia rural. Vigo. Xerais.

Bouhier, A. (2001). Galicia: ensaio xeográfico de análise e inerpretación dun vello complexo agrario. Xunta de Galicia (edición Original de 1979).

Corbacho, B. (2017). Intensification of a peasant agriculture and soil fertility in an Atlantic territory: Galicia, 1750-1900 (Tesis Doctoral). Universidade de Santiago de Compostela. Santiago de Compostela (España).

Ostrom, E. (2011). El gobierno de los bienes comunes. La evolución de las instituciones de acción colectiva. FCE.

Soto, D. (2006). Historia dunha agricultura sustentabel. Transformacións produtivas na agricultura galega contemporánea. Santiago, Xunta de Galicia.

\section{Capítulo de libro:}

Fernández, X., Soto, D.; (2004). "Política forestal e conflictividade nas terras comunais de Galicia durante o franquismo (1939-1975)" en D. Freire, I. Fonseca y P. Godinho (eds.), Mundo Rural, Transformaçao e resistencia na Península Ibérica (século XX), Lisboa, Colibri, pp. 225-249 